\title{
Does pre-operative psychological distress affect patient satisfaction after primary total hip arthroplasty?
}

\author{
Munier Hossain ${ }^{1 *+}$, Daniel J Parfitt ${ }^{1 \dagger}$, David J Beard ${ }^{2 \dagger}$, Clare Darrah ${ }^{3 \dagger}$, John Nolan ${ }^{3+}$, David W Murray ${ }^{2 \dagger}$ and \\ Glynne Andrew ${ }^{1+}$
}

\begin{abstract}
Background: There are concerns that pre-operative psychological distress might be associated with reduced patient satisfaction after total hip replacement (THR).

Methods: We investigated this in a multi-centre prospective study between January 1999 and January 2002. We dichotomised the patients into the mentally distressed $(\mathrm{MHS} \leq 56)$ and the not mentally distressed (MHS > 56) groups based on their pre-operative Mental Health Score (MHS) of SF36.

Results: 448 patients (340 not distressed and 108 distressed) completed the patient satisfaction survey. Patient satisfaction rate at five year was $96.66 \%$ (415/448). There was no difference in patient satisfaction or willingness to have the surgery between the two groups. None of pre-operative variables predicted five year patient satisfaction in logistic regression.
\end{abstract}

Conclusions: Patient satisfaction after surgery may not be adversely affected by pre-operative psychological distress.

\section{Background}

Total Hip Replacement (THR) is recognised as a very successful surgical intervention with high patient satisfaction [1]. However, it is estimated that a significant proportion of the patients may remain unsatisfied following THR [2]. Researchers have analysed various preoperative patient characteristics in an attempt to identify the best candidates for surgery and to identify the factors that are likely to predict poor patient satisfaction postoperatively [3-7]. The effect of patients' preoperative mental health on the outcome of joint replacement surgery has become an area of interest and has received some attention $[8,9]$. Researchers have shown that patients with preoperative mental distress are less likely to benefit after knee arthroplasty but the effect on outcome is less clear with THR [2,8-10].

\footnotetext{
* Correspondence: munierh@doctors.org.uk

† Contributed equally

'Department of Trauma and Orthopaedics, Ysbyty Gwynedd, Bangor LL57 2PW, UK

Full list of author information is available at the end of the article
}

This prospective study investigated what effect preoperative mental health-assessed as psychological distress- had on patient satisfaction after THR. Our null hypothesis was that there was no difference in patient satisfaction after THR between patients who reported mental distress before surgery and those who did not.

\section{Methods}

The Exeter Primary Outcome Study (EPOS) was a multi centre prospective cohort study of outcome after primary THR. Patients were consecutively recruited between January 1999 and January 2002 at seven centres across England and Scotland. Patients underwent THR using a cemented Exeter femoral stem component (Stryker Howmedica Osteonics, Mahwah, New Jersey). A variety of cemented and uncemented acetabular components were used. Patients were included if they were undergoing primary hip arthroplasty with an Exeter cemented femoral stem and were willing and able to give consent to participate in the study. The study conformed to the Helsinki declaration and to local 
legislation. North Western Multiple Centre Research Ethics Committee and the local research ethics committees in all the participating centres gave ethical approval for conducting the study. Four centres collected data for SF-36 and patient satisfaction survey. We prospectively recorded patients' demographic and clinical status. We also recorded SF-36 score before and after surgery. We obtained the Medical Outcome Survey Short Form 36 (SF-36) score to assess physical, mental and functional status of the patients. The SF-36 is a widely used generic instrument designed to measure patients' health related quality of life. Higher score in SF36 for a domain means better physical or mental state (0-100 range). We used the mental health (MHS) score of SF-36 as a validated marker of mental distress. Patients were dichotomised into a group classed as self-reported psychological distress with a mental health score of fifty-six or less $(\mathrm{MHS} \leq 56)$ and those not psychologically distressed (MHS > 56) based on their pre-operative MHS. The cut-off value of 56 has been suggested by the European Mindful Working Party [11]. At five year follow-up we also invited the patients to complete a patient satisfaction survey. 448/819 completed the patient satisfaction survey.

The patient satisfaction survey was a seven item questionnaire that included questions on pain relief, improvement in ability to do house or garden work, improvement in ability to do recreational activities, overall satisfaction, improvement of quality of life, residual concerns about the operated hip, and whether patients would be prepared to have the same procedure again. The first four questions were graded on a four point likert scale $(1=$ very satisfied, $2=$ somewhat satisfied, $3=$ somewhat dissatisfied, $4=$ very dissatisfied). Quality of life improvement was indicated by a six point likert scale $(1=$ more than imagined, 2 = great improvement, $3=$ moderate, $4=$ little, $5=$ none, $6=$ worse). Patient concern was indicated by a dichotomous reply (yes/no). The satisfaction survey is reproduced in detail in table 1. Similar questionnaires have been used by various published studies to indicate patient satisfaction following joint replacement $[12,13]$. Besides, the single question alone (overall satisfaction) has been well validated as a correct indicator of patient satisfaction [14]. Patients were followed up in the outpatient clinic where they completed the patient satisfaction and SF-36 questionnaires. We retrospectively reviewed the database to analyse the relationship between pre-operative psychological distress and post-operative patient satisfaction for the 448 patients (340 not distressed and 108 distressed) who had complete data for pre-operative psychological distress and five year patient satisfaction.

All eligible patients were invited to participate in the study. Patient recruitment varied between the centres but was between $80 \%-90 \%$ of eligible patients. The geographical area covered by the participating hospitals was wide and included both university teaching and district general hospitals that included urban as well as rural locations and represented both affluent as well as inner city suburbs. The catchment area of the four combined units included over a million people.

\section{Statistics}

We used SPSS 16.0 (SPSS Inc, Illinois, USA) statistical software for statistical analysis. The Mann-Whitney test was used for non-parametric data and $t$ test for parametric data. Differences in proportions were tested using the $\chi^{2}$ test or, where necessary, Fisher's exact test. In all analyses we used the two tailed test. We considered results significant at $p<0.05$. We performed binary logistic regression to identify the variables predictive of patient satisfaction at five years after surgery. We dichotomised the four point patient satisfaction score into the satisfied ("very satisfied" or "somewhat satisfied") or the not satisfied ("somewhat dissatisfied "or "very dissatisfied") groups. The dichotomised variable was introduced as the dependent variable. Independent variables were the various baseline characteristics and pre-operative SF36 domain scores. Variables were initially tested for significance using univariate analysis and significant variables introduced in a multivariate analysis to test for significance and to identify adjusted odds ratios. Different authors have used different cut-off MHS values to define mental distress [8]. We therefore performed a sensitivity analysis with a cut-off MHS value of 50 to test the robustness of our conclusion. We also stratified the results of the patient satisfaction survey according to gender.

\section{Results}

The patients' demographics and pre-operative details are shown in Table 1 . Females were significantly more common in the psychologically distressed group. The distressed group also weighed less and were shorter in height compared to the non - distressed group. The group reporting pre-operative psychological distress had significantly worse pre-operative SF-36 scores in all domains (Table 2).

\section{Patient satisfaction}

Overall patient satisfaction was high with $3.4 \%$ of patients $(15 / 448)$ remaining "somewhat dissatisfied" or "very dissatisfied" at five years after surgery (Table 3 ). The patients not reporting pre-operative psychological distress reported significantly lower level of pain in the patient satisfaction questionnaire $(\mathrm{p}=0.026)$, were more able to do recreational activities $(p=0.039)$ and were less concerned about the operated hip $(\mathrm{p}=0.007)$ 
Table 1 Patient satisfaction survey

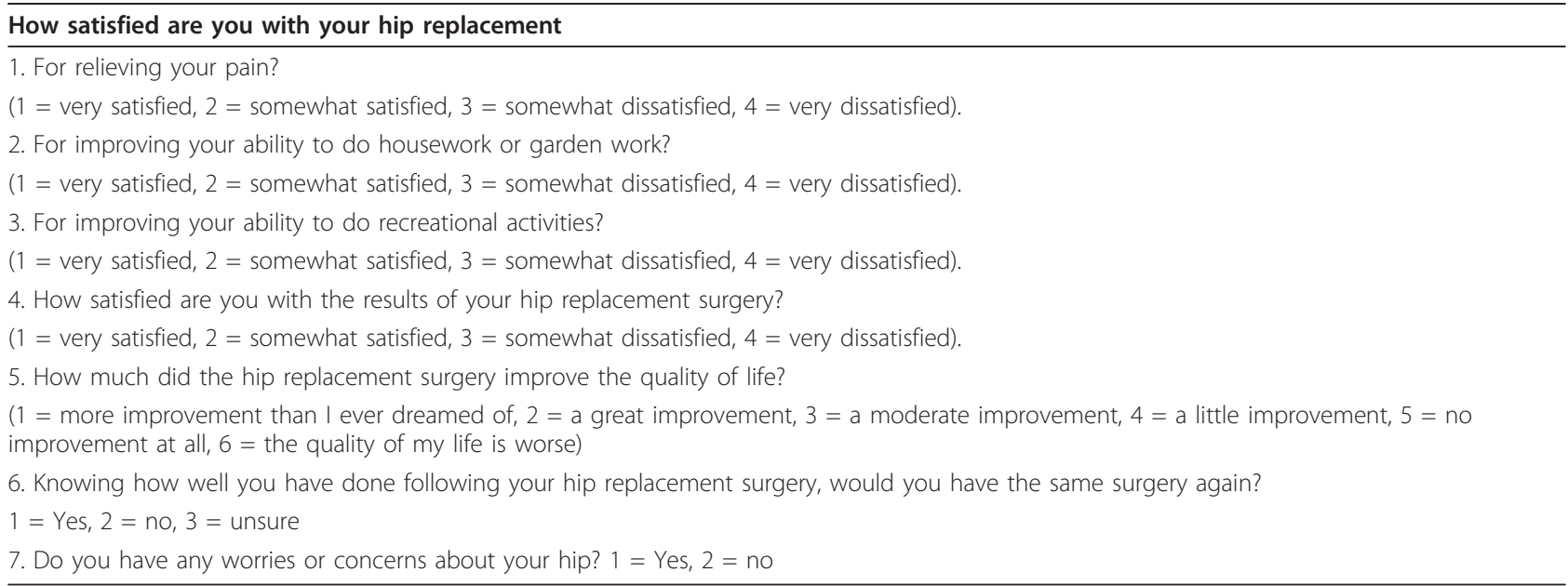

compared to the distressed group. However, this did not seem to affect the overall satisfaction $(\mathrm{p}=0.410)$, ability to do housework ( $\mathrm{p}=0.063)$, perception of improvement in quality of life $(\mathrm{p}=0.349)$ or the willingness to have the surgery again $(p=0.219)$ between the two groups at five year following surgery. Gender, primary diagnosis and various domains of SF-36 score were all significantly independently predictive of five year patient satisfaction. However, when the effects of the significant variables were adjusted for in a multivariate analysis their effects were no longer significant and none of the variables were predictive of patient satisfaction.

\section{Effect of possible confounders}

We compared the incidence of post-operative complications or further hip surgery up to five years following

Table 2 Patient baseline characteristics with mean values and range in brackets

\begin{tabular}{|c|c|c|c|}
\hline Patient characteristics & Non distressed $(n=340)$ & Distressed $(n=108)$ & $p$ value \\
\hline Gender: M:F & $147: 192$ & $33: 75$ & 0.018 \\
\hline Height: ( cm) & $167.95(146-189)$ & $165.90(145-185)$ & 0.047 \\
\hline Weight ( kg) & $78.01(48-154)$ & $74.67(44-126)$ & 0.058 \\
\hline Age & 64.37 (29-90) & $64.70(23-85)$ & 0.772 \\
\hline Affected hip & L 163, R 167 & L $38 R 70$ & 0.026 \\
\hline Occupation & $\begin{array}{l}\text { Unemployed/retired } 218 \\
\text { professional } 46 \\
\text { other } 66\end{array}$ & $\begin{array}{l}\text { Unemployed/retired } 76 \\
\text { housewife } 12 \\
\text { other } 20\end{array}$ & 0.040 \\
\hline Diagnosis & $\begin{array}{l}\text { Primary OA } 271 \\
\text { Secondary OA } 28 \\
\text { Other } 41\end{array}$ & $\begin{array}{l}\text { Primary OA } 90 \\
\text { Secondary arthritis } 6 \\
\text { Other } 12\end{array}$ & 0.080 \\
\hline Co-existent disease & 252 & 90 & 0.052 \\
\hline Corticosteroid use & 47 & 9 & 0.693 \\
\hline NSAID & 163 & 53 & 1.000 \\
\hline Anticoagulant use & 39 & 21 & 0.054 \\
\hline Charnley category & A 168, B 62, C 90 & A $50, B 19$, C 35 & 0.559 \\
\hline MHS & $79(60-100)$ & $43(0-56)$ & 0.000 \\
\hline General health & $71(20-100)$ & $59(10-97)$ & 0.000 \\
\hline Bodily pain & $30(0-100)$ & $18(0-94)$ & 0.006 \\
\hline Physical functioning & $21(0-90)$ & $13(0-95)$ & 0.002 \\
\hline Social functioning & $50(0-100)$ & $26(0-100)$ & 0.000 \\
\hline Vitality & $44(0-95)$ & $26(0-70)$ & 0.001 \\
\hline Role emotional & $59(0-100)$ & $15(0-100)$ & 0.000 \\
\hline Role physical & $11(0-100)$ & $5(0-100)$ & 0.022 \\
\hline Surgical approach & Posterior 79, lateral 160 & Posterior 31, lateral 50 & NA \\
\hline
\end{tabular}


Table 3 Patient satisfaction survey

\begin{tabular}{|c|c|c|c|c|c|}
\hline Overall satisfaction & Very satisfied & $\begin{array}{l}\text { Somewhat } \\
\text { satisfied }\end{array}$ & $\begin{array}{l}\text { Somewhat } \\
\text { dissatisfied }\end{array}$ & $\begin{array}{c}\text { Very } \\
\text { dissatisfied }\end{array}$ & Total \\
\hline No distress & $280(82.4 \%)$ & $50(14.7 \%)$ & $8(2.4 \%)$ & $2(0.6 \%)$ & $340(100 \%)$ \\
\hline Distress & $81(75.0 \%)$ & $22(20.4 \%)$ & $4(3.7 \%)$ & $1(0.9 \%)$ & $108(100 \%)$ \\
\hline Total & $361(80.6 \%)$ & $72(16.1 \%)$ & $12(2.7 \%)$ & $3(0.7 \%)$ & $448(100 \%)$ \\
\hline Pain relief & Very Satisfied & Somewhat Satisfied & Somewhat Dissatisfied & Very Dissatisfied & Total \\
\hline No distress & $281(83.1 \%)$ & $46(13.6 \%)$ & $10(3.0 \%)$ & $1(0.3 \%)$ & $338(100 \%)$ \\
\hline Distress & 79(73.1\%) & $22(20.4 \%)$ & $4(3.7 \%)$ & $3(2.8 \%)$ & $108(100 \%)$ \\
\hline Total & $360(80.7 \%)$ & $68(15.2 \%)$ & $14(3.1 \%)$ & $4(0.9 \%)$ & $446(100 \%)$ \\
\hline $\begin{array}{l}\text { Any concerns regarding operated } \\
\text { hip }\end{array}$ & Yes & No & & & Total \\
\hline No distress & $66(19.5 \%)$ & $273(80.5 \%)$ & & & $339(100 \%)$ \\
\hline Distress & $34(32.4 \%)$ & $71(67.6 \%)$ & & & $105(100 \%)$ \\
\hline Total & $100(22.5 \%)$ & $344(77.5 \%)$ & & & $444(100 \%)$ \\
\hline Have same surgery again? & Yes & No & Unsure & & Total \\
\hline No distress & $296(87.3 \%)$ & $9(2.7 \%)$ & $34(10.0 \%)$ & & $339(100 \%)$ \\
\hline Distress & $88(81.5 \%)$ & $6(5.6 \%)$ & 14(13.0\%) & & $108(100 \%)$ \\
\hline Total & $384(85.9 \%)$ & $15(3.4 \%)$ & $48(10.7 \%)$ & & $447(100 \%)$ \\
\hline Quality of life improvement & $\begin{array}{l}\text { Great or more than } \\
\text { imagined }\end{array}$ & Moderate & Little & None or worse & Total \\
\hline No distress & $296(87.3 \%)$ & $32(9.4 \%)$ & $5(1.5 \%)$ & $6(1.8 \%)$ & $339(100 \%)$ \\
\hline Distress & $85(78.7 \%)$ & $16(14.8 \%)$ & $4(3.7 \%)$ & $3(2.8 \%)$ & $108(100 \%)$ \\
\hline Total & $381(85.3 \%)$ & $48(10.7 \%)$ & $9(2.0 \%)$ & $9(2.0 \%)$ & $447(100 \%)$ \\
\hline Ability to do house/gardenwork & Very satisfied & Somewhat satisfied & Somewhat dissatisfied & Very dissatisfied & Total \\
\hline No distress & $211(63.7 \%)$ & $95(28.7 \%)$ & $17(5.1 \%)$ & $8(2.4 \%)$ & $331(100 \%)$ \\
\hline Distress & $42(43.3 \%)$ & $34(39.1 \%)$ & 7(8.0\%) & $4(4.6 \%)$ & 87 (100\%) \\
\hline Total & $253(60.5 \%)$ & $129(30.9 \%)$ & $24(5.7 \%)$ & $12(2.9 \%)$ & $418(100 \%)$ \\
\hline Ability to do recreational activities & Very Satisfied & Somewhat Satisfied & Somewhat Dissatisfied & Very Dissatisfied & Total \\
\hline No distress & $187(56.5 \%)$ & 105(31.7\%) & $27(8.2 \%)$ & $12(3.6 \%)$ & $331(100 \%)$ \\
\hline Distress & $35(40.7 \%)$ & $33(38.4 \%)$ & $12(14.0 \%)$ & $6(7.0 \%)$ & $86(100 \%)$ \\
\hline Total & 222 (53.2\%) & 138(33.1\%) & 39 (9.4\%) & 18 (4.3\%) & 417 (100\%) \\
\hline
\end{tabular}

the index procedure to assess if postoperative complications or further hip surgery might have acted as a confounding factor that affected patient satisfaction. There was no significant difference in major postoperative complications $(\mathrm{p}=0.891)$ or further hip surgery $(\mathrm{p}=$ 0.969 ) between the two groups of patients (Table 4).

\section{Sensitivity analysis}

Sensitivity analysis with a cut-off MHS value of 50 did not affect the results of patient satisfaction.
We also stratified the patient satisfaction survey according to gender. As previously noted, patients reporting pre-operative psychological distress in both genders reported significantly higher level of pain (male $\mathrm{p}=0.007$, female $\mathrm{p}=0.025$ ). The pattern of patient satisfaction with regard to patients' ability to do housework (male $\mathrm{p}=0.671$, female $\mathrm{p}=0.238$ ), ability to do recreational activities (male $\mathrm{p}=0.609$, female $\mathrm{p}=$ 0.151 ), improvement in quality of life (male $p=0.567$, female $\mathrm{p}=0.710$ ) and in willingness to have the surgery

Table 4 Post-operative complications and further hip surgery

\begin{tabular}{lccccc}
\hline Post-operative complications & Very satisfied & Somewhat satisfied & Somewhat dissatisfied & Very dissatisfied & Total \\
\hline No & $301(81.4 \%)$ & $58(15.7 \%)$ & $10(2.7 \%)$ & $1(0.3 \%)$ & $370(100 \%)$ \\
Yes & $4(77.8 \%)$ & $10(18.5 \%)$ & $2(3.7 \%)$ & $0(0.0 \%)$ & $54(100 \%)$ \\
Total & $361(80.9 \%)$ & $72(16.0 \%)$ & $12(2.8 \%)$ & $1(0.2 \%)$ & $424(100 \%)$ \\
Further hip surgery & Very Satisfied & Somewhat Satisfied & Somewhat Dissatisfied & Very Dissatisfied & Total \\
No & $337(80.8 \%)$ & $67(16.1 \%)$ & $12(2.9 \%)$ & $1(0.2 \%)$ & $417(100 \%)$ \\
Yes & $6(85.7 \%)$ & $1(14.3 \%)$ & $0(0.0 \%)$ & $0(0.0 \%)$ & $7(100 \%)$ \\
Total & $343(80.9 \%)$ & $68(16.0 \%)$ & $12(2.8 \%)$ & $1(0.2 \%)$ & $444(100 \%)$ \\
\hline
\end{tabular}


again (male $\mathrm{p}=0.612$, female $\mathrm{p}=0.399$ ) was the same between the sexes and not significantly different for preoperative psychological distress. However, unlike the previously observed trend, overall satisfaction differed between the sexes. Men reporting pre-operative psychological distress were significantly more likely to remain overall unsatisfied after surgery $(p=0.016)$ whereas women were not $(\mathrm{p}=0.869$. Similarly, men reporting pre-operative psychological distress were highly likely to maintain further worry or concern regarding the operated hip $(\mathrm{p}=0.001)$ whereas women were not $(\mathrm{p}=$ 0.227).

\section{Discussion}

Our results indicate that women are more likely to report pre-operative mental distress than men and the mentally distressed group have worse absolute values for all domains of SF-36 score. However, even though patients with pre-operative mental distress report somewhat higher pain and may have more concerns with their operated hip, five year patient satisfaction following THR is very high and is not affected by patients' pre-operative mental distress. Men who reported preoperative psychological distress were more likely to remain less overall satisfied and less satisfied with pain relief. There appears to be accumulating evidence that patient satisfaction after surgery is multifactorial and complicated. Our results suggest that it may not be possible to predict patient satisfaction at five years after surgery by considering the pre-operative patient variables in isolation. It is intriguing that although the non distressed group reported significantly less pain this did not appear to affect patient satisfaction. Pain relief is known to be an important predictor of post operative satisfaction. On closer scrutiny the difference in pain between the two groups appear minimal (96.7\% satisfaction with pain in no distress group compared to $93.5 \%$ satisfaction with pain in the distressed group). However, it is notable that we found no significant difference in willingness to go through with surgery again between the two groups. Previously researchers have reported that willingness to go through with surgery again validated a clinically important difference in WOMAC scoring [15]. This would suggest that even though statistically significant, the clinical significance of difference in pain between the two groups may be low and as such did not affect overall patient satisfaction.

The clinical significance of difference in patient satisfaction when stratified for gender remains uncertain and needs to be further investigated. We are not aware of any previous study that has indicated this aspect of patient satisfaction. Previous studies had indicated that gender in isolation does not predict patient satisfaction [13]. It is notable that men reporting pre-operative psychological distress not only remained less satisfied after surgery they were also less satisfied with pain compared to women and remained more concerned after surgery even though there was no difference in reported satisfaction with household or recreational activities. We speculate that this difference might be due to difference in expectation of pain relief between the two groups. Indeed previous reports have indicated that most patients expect improvement in pain and satisfaction is related to patients' previous expectation [13]. Our results also agree with a previous report that post-operative functional capacity does not necessarily correlate with patient expectation [16].

Because of variation in outcome following joint replacement [17], some quarters have expressed reservation about operating on patients who are likely to have poor response [9]. Various studies have therefore attempted to identify possible poor responders following surgery $[9,18]$. However, it should also be borne in mind that results from large cohort studies may not be applicable at an individual level.

A degenerative joint is a source of chronic pain and physical dysfunction and both of these factors have known association with impaired mental health [19-21]. There are varying reports about the effect of emotional distress or illness on outcomes after joint arthroplasty with reports suggesting both reduced health gain [22-25] and substantial improvement [8]. Although the volume of research on knee replacement is substantial very few researchers have addressed THR patients. A recent study suggested that caution and possibly additional treatment should be employed for patients with mental distress awaiting THR because of the risk of dissatisfaction [9]. Another small study previously contended that even though the health benefit gained by them may be no less, distressed patients reported less absolute WOMAC score pre and postoperatively after THR [10].

We do not know how representative our study population is of the general population undergoing or awaiting THR. Because this is a report from a few selfselected centres it is possible that selection or referral bias might have affected the study population. We also did not record patient expectation. Some have claimed that patient satisfaction after surgery is closely related to their expectation [25].

\section{Conclusions}

The current study demonstrates that five year patient satisfaction after THR is very high and although patients with pre-operative mental distress report less pain relief they remain no less satisfied than those without any mental distress. Willingness to experience the procedure again or the perception of improvement in quality of life 
is similar in both groups of patients. Patients with preoperative psychological distress are no more likely to be poor responders after surgery than those not distressed.

\section{Acknowledgements}

The authors wish to thank Kate Honeybill, Polly Winter and Marianna Pissides (Clinical Research Associates), and Aly Nicholl, Lene Guerney (Research Co-ordinators) of Stryker Howmedica Osteonics (Newbury, United Kingdom) for their help in collating the Exeter Primary Outcome Study (EPOS) data. The following people are principal investigators of the group: Mr. G Andrew (Chief investigator), Mr. J. Nolan, Mr. A. Hammer, Mr. M. Fordyce, Mr. P. Gibson, Prof. D. Murray and Mr. K. Tuson. The following are study co-ordinators for the EPOS group: A. Potter, A. McGovern, K. Reilly, C. Jenkins, A. Cooper, C. Darrah, L. Cawton, A. Nicholl, P. Inaparthy and C. Pitchfork. The seven centres involved in the study are: Woodend Hospital, Aberdeen; Hope Hospital, Salford; Nuffield Orthopaedic Centre, Oxford; Norfolk and Norwich University Hospital, Norwich; Northern General Hospital, Sheffield; Kent and Sussex Hospital, Tunbridge Wells and The Horder Centre, Crowborough, United Kingdom.

\section{Author details}

'Department of Trauma and Orthopaedics, Ysbyty Gwynedd, Bangor LL57 2PW, UK. ${ }^{2}$ Nuffield Department of Orthopaedic Surgery, Nuffield Orthopaedic Centre NHS Trust Headington, Oxford OX3 7LD, UK. ${ }^{3}$ Norfolk and Norwich University Hospital Norwich, NR4 7UY, UK.

\section{Authors' contributions}

$D B, C D, D M, J N$ and GA conceived and designed the study. CD, MH and DP gathered the data, MH, DP, DB, DM and GA analysed the data, MH, DP and GA wrote the initial draft. DB, DM and GA ensured the accuracy of data and analysis. All authors have given final approval to the draft.

\section{Competing interests}

this study was financed by Stryker, UK.

Received: 9 November 2010 Accepted: 1 June 2011

Published: 1 June 2011

\section{References}

1. Jones CA, Voaklander DC, Johnston DW, suarez-Almazor ME: Health related quality of life outcomes after total hip and knee arthroplasties in a community based population. J Rheumatol 2000, 27(7):1745-1752.

2. Gandhi R, Davey JR, Mahomed NN: Predicting patient dissatisfaction following joint replacement surg. J Rheumatol 2008, 35(12):2415-8.

3. Andrew JG, Palan J, Kurup HV, Gibson P, Murray D, Beard DJ: Obesity in total hip replacement. J Bone Joint Surg [Br] 2008, 90-B:424-429.

4. Jones CA, Voaklander DC, Johnston DW, Suarez-Almazor ME: The effect of age on pain, function, and quality of life after total hip and knee arthroplasty. Arch Intern Med 2001, 161(3):454-460.

5. March LM, Cross MJ, Lapsley H, Brnabic AJ, Tribe KL, Bachmeier CJ, Courtenay BG, Brooks PM: Outcomes after hip or knee replacement surgery for osteoarthritis. A prospective cohort study comparing patients' quality of life before and after surgery with age-related population norms. Med J Aust 1999, 171(5):235-238.

6. Weng HH, Fitzgerald J: Current issues in joint replacement surgery. Curr Opin Rheumatol 2006, 18(2):163-169.

7. Santaguida PL, Hawker GA, Hudak PL, Glazier R, Mahomed NN, Kreder HJ, Coyte PC, Wright JG: Patient characteristics affecting the prognosis of total hip and knee joint arthroplasty: a systematic review. Can J Surg 2008, 51(6):428-436.

8. Lingard EA, Riddle D: Impact of Psychological Distress on Pain and Function Following Knee Arthroplasty. J Bone Joint Surg Am 2007, 89:1161-1169

9. Rolfson O, Dahlbarg LE, Nilsson JA, Malchau H, Garelick G: Variables determining outcome in total hip replacement surgery. Journal Bone Joint Surg 2009, 91-B:157-161.

10. Riediger W, Doering S, Krismer M: Depression and somatisation influence the outcome of total hip replacement. Int Orthop 2010, 34:13-18.
11. European community Health Indicators Monitoring: [http://www. healthindicators.eu], (accessed on 24 May, 2011).

12. Mancuso CA, Salvati EA, Johanson NA, Peterson ME, Charlson ME: Patients' expectations and satisfaction with total hip arthroplasty. J Arhtroplasty 1997, 12:387-396.

13. Anawake RE, Jenkins PJ, moran M: Predicting dissatisfaction after total hip arthroplasty: a study of 850 patients. J Arthroplasty 2011, 26:209-213.

14. Robertson O, dunbar MJ: Patient satisfaction compared with general health and disease-specific questionnaires in knee arthroplasty patients. J Arthroplasty 2001, 16:476-482.

15. Chesworth BM, Mahomed NN, Bourned RB: Willingness to go through surgery again validated the WOMAC clinically important difference from THR/TKR surgery. J Clin Epidemiol 2008, 61:907-918.

16. Vissers MM, de Groot IB, Reijman M, Bussman JB, Stam HJ, Verhaar JAN: Functional capacity and actual daily activity do not contribute to patient satisfaction after total knee arthroplasty. BMC Musculoskeletal Disorders 2010, 11:121.

17. Jinks C, Lewis M, Croft P: Health status after hip or knee Arthroplasty. Ann Rheum Dis 2003, 62:700-701.

18. Nilsdotter AK, Petersson IF, Roos EM, Lohmander LS: Predictors of patient relevant outcome after total hip replacement for osteoarthritis: a prospective study. Ann Rheum Dis 2003, 62(10):923-930.

19. Beesdo K, Jacobi F, Hoyer J, Low NC, Höfler M, Wittchen HU: Pain associated with specific anxiety and depressive disorders in a nationally representative population sample. Soc Psychiatry Psychiatr Epidemiol 2010, 45:89-104.

20. Beesdo K, Hoyer J, Jacobi F, Low NC, Höfler M, Wittchen HU: Association between generalized anxiety levels and pain in a community sample: Evidence for diagnostic specificity. J Anxiety Disord 2009, 23:684-693.

21. Sareen J, Cox BJ, Clara I, Asmundson GJ: The relationship between anxiety disorders and physical disorders in the U.S. National Comorbidity Survey. Depress Anxiety 2005, 21(4):193-202.

22. Ayers DC, Frankiln PD, Trief PM, Ploutz-Snyder R, Freund D: Psychological attributes of preoperative total joint replacement patients: implications for optimal physical outcome. J Arthroplasty 2004, 19:125-130.

23. Ayers DC, Franklin PD, Ploutz-Snyder R, Boisvert CB: Total knee arthroplasty outcome and coexisting physical and emotional illness. Clin Orthop Relat Res 2005, 440:157-161.

24. Lingard EA, Katz JN, Wright EA, Sledge CBJ: Predicting the outcome of total knee arthroplasty. Bone Joint Surg Am 2004, 86-A(10):2179-86.

25. Faller H, Kirschner S, König A: Psychological distress predicts functional recovery at three and twleve months after total knee arthroplasty. Gen Hosp Psychiatry 2003, 25(5):372-373.

Pre-publication history

The pre-publication history for this paper can be accessed here: http://www.biomedcentral.com/1471-2474/12/122/prepub

doi:10.1186/1471-2474-12-122

Cite this article as: Hossain et al: Does pre-operative psychological distress affect patient satisfaction after primary total hip arthroplasty? BMC Musculoskeletal Disorders 2011 12:122.

\section{Submit your next manuscript to BioMed Central and take full advantage of:}

- Convenient online submission

- Thorough peer review

- No space constraints or color figure charges

- Immediate publication on acceptance

- Inclusion in PubMed, CAS, Scopus and Google Scholar

- Research which is freely available for redistribution 